\title{
Obstetric emergencies during the COVID-19 lockdown period: a case series
}

\author{
Ananya Vasudhar*, Anita S., Gayatri L. Patil, Shridevi A. S., Tejaswi V. Pujar, Renuka
}

Department of Obstetrics and Gynaecology, S. S. Institute Medical Sciences and Research Centre, Karnataka, India

Received: 24 August 2020

Revised: 05 October 2020

Accepted: 06 October 2020

\section{*Correspondence:}

Dr. Ananya Vasudhar,

E-mail: ananyavasudhar@gmail.com

Copyright: (c) the author(s), publisher and licensee Medip Academy. This is an open-access article distributed under the terms of the Creative Commons Attribution Non-Commercial License, which permits unrestricted non-commercial use, distribution, and reproduction in any medium, provided the original work is properly cited.

\section{ABSTRACT}

Obstetric emergencies during COVID-19 pandemic pose an enormous challenge to the concerned obstetrician. Risk stratification during obstetric triage will guide in the initial assessment \& planning of further management to reduce maternal and fetal morbidity and mortality rates. As the health system adapts to cope with this pandemic, special attention needs to be given to the several moral and ethical dilemmas that may occur during patient care.

Keywords: COVID-19, Lockdown, Obstetric emergencies, Pandemic obstetrics

\section{INTRODUCTION}

An obstetric emergency is defined as an obstetric complication or situation of serious and often dangerous nature, developing suddenly and unexpectedly and demanding immediate attention to save life. ${ }^{1,2}$ Obstetric emergencies constitute cases like antepartum hemorrhage, pregnancy-induced hypertension, sepsis, thromboembolism, amniotic fluid embolism, and ectopic pregnancy. ${ }^{3,4}$

In 2005 statistics claim that maternal deaths were estimated to be 69400 in India. ${ }^{5}$

Most maternal deaths were attributed to direct obstetric causes (82\%). MMR in India has not declined significantly in the past 15 years. The three main causes of these maternal deaths are antepartum hemorrhage, sepsis, and eclampsia.

Presently, on an average, about 20 to 30 obstetric emergencies are seen every month at the obstetrics and gynecology department of our institute. During the lockdown period, the obstetric emergencies we faced in our institution were ectopic pregnancies, pregnancyinduced hypertension, placenta previa, abruptio placenta, and complications due to gestational diabetes mellitus. So, a better knowledge of the spectrum, characteristics, and outcomes of the disease involving critical obstetric patients is the first step towards achieving safe motherhood status.

Different parts of the country are seeing different levels of COVID-19 activity. India nationally is in the acceleration phase of the pandemic. Testing is critical for risk mitigation, data collection, and directing critical resources, including PPE. Pregnant women admitted with suspected COVID-19 or who develop symptoms suggestive of COVID-19 during admission should be prioritized for testing, particularly in high prevalence areas6. Pregnant patients with comorbidities may be at increased risk for severe illness consistent with the general population with similar comorbidities. To date, there is no conclusive evidence of vertical transmission of COVID-19., ${ }^{7,8}$ ICMR recommends pregnant women residing in clusters/containment area or large migration gatherings/evacuation centers from hotspot districts 
presenting in labor or likely to deliver in the next five days should be tested even if asymptomatic. ${ }^{9}$

Historically, respiratory infections in pregnant individuals have been thought to increase their risk of severe morbidity and mortality. ${ }^{10}$ The knowledge that we have on the obstetric implications of the SARS-CoV-2 virus is limited and constantly evolving.

Community mitigation efforts to control the spread of COVID-19 have been implemented across India. A strict lockdown was implemented in Davangere, Karnataka. Although these efforts are important, obstetricians faced a unique issue due to the unintended effect that it had on limiting access to routine prenatal care. We had to account for the fact that private practitioners and private nursing homes were shut down during the lockdown period. Of those who were still examining patients, where only seeing emergency cases, based on their clinical judgment. While the clinicians themselves may be available, the unavailability of managerial, administrative, nursing, and other support staff posed logistical and operational challenges to running a health care facility in times of the pandemic. Ob-gyns and other obstetric care professionals in our institute continued to provide medically necessary prenatal care, referrals, and consultations. While elective surgeries were rescheduled and planned at a later date, obstetric emergencies need to be examined and treated on an urgent basis. Ob-gyns and other prenatal care professionals also had to consider creating a plan to address the possibility of a decreased health care workforce, a potential shortage of personal protective equipment, and limited isolation rooms and maximized the use of telemedicine. Patients would contact the doctors previously treating them and we had to decide if their presenting complaints needed immediate medical attention or not.

COVID-19 infection is highly contagious, and this was taken into consideration when planning intrapartum care. Until proven otherwise suspected cases were considered as positive cases and all medical staff caring for potential or confirmed COVID-19 patients used personal protective equipment (PPE), including respirators (eg N95 respirators) until the patient's status was known. Suspected cases were directly taken to an isolation ward in the labor room on arrival. The treating doctors, nursing, and supporting staff donned N95 masks, gowns, gloves, head, and shoe covers, and face shield provided in the PPE. A throat swab was taken and sent after stabilizing the patient.

During a pandemic, teleconsultation becomes a lifesaving tool, as it minimizes exposure risks for both patients and healthcare professionals. ${ }^{11}$ During the lockdown, it helped in "forward triage"-the sorting of patients before they arrive in the department. Pregnant people might be at increased risk for severe illness from COVID-19 compared to non-pregnant people probably due to changes in anatomy, endocrine, and immune factors during pregnancy. Weighing the risks of delaying treatment versus chances of contracting the infection with compromised immunity was a difficult choice to make. This touches upon the ethical question of assigning priority such as (i) how to distribute their scarce medical resources among Covid-19 patients; (ii) how to distribute limited resources between COVID and non-COVID patients; and (iii) whether the lockdown as a measure aimed to reduce and prevent the transmissions of COVID-19 infringes the individual right to seek healthcare.

As the health system adapts to cope with this pandemic, special attention needs to be given to the several moral and ethical dilemmas that may occur during patient care. Stigma-related issues tend to arise for patients as well as care providers. We need to provide better access to health care for the patients to prevent morbidity and mortality due to preventable causes, and also develop a robust healthcare system that can weather the current storm and sustain itself in the post-COVID era. This study was undertaken to analyze the case profiles of all the obstetric emergencies, their approach, and management during the lockdown period.

\section{Aims and objectives}

Aim and objectives were to study the demographics, clinical characteristics, and outcomes of patients presenting as obstetric emergencies and to revise management protocols in the management of a suspected COVID-19 obstetric emergency case.

\section{METHODS}

A prospective observational study was undertaken at the Department of Obstetrics and Gynecology; SSIMS \& RC, Davangere. Statistical analysis will be performed by using the Chi square test and Student's t-test. A study was conducted on 50 booked or unbooked patients received at the emergency department of our hospital. History of the patient including the residential address, signs, and symptoms pertaining to COVID-19 infection, and the presenting condition will be taken from the patient and patient's attenders. If the patient is suspected to be from a COVID-19 containment area or primary contact to a positive corona patient or having any symptoms; then the patient will be received according to ICMR guidelines.

If suspected, the doctor, nursing staff, the anesthetist will be examining the patient in full PPE kit. The patient's throat and nasopharyngeal swab will be sent. The treating personnel should be wearing an N95 mask. Required investigations will be done. An emergency operative procedure will be performed in an OT dedicated to corona patients. 


\section{RESULTS}

\section{Sociodemographic characteristics}

Here, Table 1 shows that most of the Pregnant women were among the age group of 26-30. The youngest woman was 19 , while the eldest was 38 years old.

Table 1: Distribution of age group.

\begin{tabular}{|lll|}
\hline Range & Numbers of patients & Percentage \\
\hline$<25$ & 5 & 10 \\
\hline $\mathbf{2 1 - 2 5}$ & 19 & 38 \\
\hline $\mathbf{2 6 - 3 0}$ & 22 & 44 \\
\hline $\mathbf{3 1 - 3 5}$ & 3 & 6 \\
\hline $\mathbf{3 6 - 4 0}$ & 1 & 2 \\
\hline Total & $\mathbf{5 0}$ & 100 \\
\hline
\end{tabular}

Here, (Table 2) shows the maximum number of patients who presented with emergencies were preterm, 16 in number, while 14 of them were term pregnancies. There were 12 postnatal patients who presented on various days of their postnatal period, while 3 of them were of postabortal state.

Table 2: Distribution of period of gestation.

\begin{tabular}{|lll|}
$\begin{array}{l}\text { Period of } \\
\text { gestation }\end{array}$ & Numbers of patients & Percentage \\
\hline Before viability & 4 & 8 \\
\hline Preterm & 16 & 32 \\
\hline Term & 14 & 28 \\
\hline Post-dated & 1 & 2 \\
\hline Post-natal & 12 & 24 \\
\hline Post abortal & 3 & 6 \\
\hline Total & 50 & 100 \\
\hline
\end{tabular}

Here, (Table 3) shows the maximum number of patients was Primigravida, 17 in number. While there was one patient who was fifth gravida. Twelve patients presented in the puerperal period.

Table 3: Distribution of obstetric score.

\begin{tabular}{|lll|}
\hline Obstetric score & Numbers of patients & Percentage \\
\hline Primi Gravida & 17 & 34 \\
\hline G2 & 8 & 16 \\
\hline G3 & 6 & 12 \\
\hline G4 & 3 & 6 \\
\hline G5 & 1 & 2 \\
\hline Post-natal & 12 & 24 \\
\hline Post abortal & 3 & 6 \\
\hline Total & 50 & 100 \\
\hline
\end{tabular}

Here, Table 4 and Figure 1 shows the maximum number of emergencies was due to pregnancy-induced hypertension and its associated complications which include- imminent eclampsia, antepartum eclampsia, postpartum eclampsia, placental eclampsia. Postpartum hemorrhage including atonic and traumatic contributed emergencies in 9 patients.

Table 4: Distribution of diagnosis.

\begin{tabular}{|lll|}
\hline Diagnosis & $\begin{array}{l}\text { Numbers } \\
\text { of patients }\end{array}$ & Percentage \\
\hline PIH and its complications & 16 & 32 \\
\hline $\begin{array}{l}\text { PPH and associated } \\
\text { complications }\end{array}$ & 9 & 18 \\
\hline IUFD & 4 & 8 \\
\hline APH & 5 & 10 \\
\hline $\begin{array}{l}\text { Cardiac disease and its } \\
\text { complications }\end{array}$ & 2 & 4 \\
\hline Ruptured ectopic & 3 & 6 \\
\hline Post abortal & 3 & 6 \\
\hline Molar pregnancy & 2 & 4 \\
\hline Febrile illness & 6 & 12 \\
\hline Total & 50 & 100 \\
\hline
\end{tabular}

\begin{tabular}{ll|}
$\square \mathrm{PIH}$ & $\square \mathrm{PPH}$ \\
$\square$ APH & Cardiac disease $\square$ Ruptured ectopic \\
$\square$ Postabortal & $\square$ Molar pregnancy $\square$ Febrile illness
\end{tabular}

Figure 1: Distribution of diagnosis.

Table 5: Distribution of presenting complaints.

\begin{tabular}{|lll|}
\hline Symptoms & $\begin{array}{l}\text { Numbers of } \\
\text { patients }\end{array}$ & Percentage \\
\hline Bleeding per Vaginum & 12 & 24 \\
\hline GTCS & 6 & 12 \\
\hline Pedal Edema & 13 & 26 \\
\hline $\begin{array}{l}\text { Loss of Fetal } \\
\text { movements }\end{array}$ & 4 & 8 \\
\hline Headache & 16 & 32 \\
\hline Blurring of vision & 12 & 24 \\
\hline Cough & 11 & 22 \\
\hline Fever & 6 & 12 \\
\hline Breathlessness & 3 & 6 \\
\hline
\end{tabular}

Here, Table 5 shows the most common symptom with which the patients had presented was a headache, which was seen in 16 patients. The second most common was 
pedal edema. Three patients presented with breathlessness.

Here, Table 6 and Figure 2 shows that 23 individuals underwent emergency lower segment caesarean section, while 5 of them had vaginal deliveries. 7 patients were given a medical line of treatment. In one case an emergency hysterotomy was done.

Table 6: Distribution by the outcome of the patient (Procedure performed).

\begin{tabular}{|lll|}
\hline Procedure & $\begin{array}{l}\text { Numbers } \\
\text { of patients }\end{array}$ & Percentage \\
\hline Conservative & 7 & 14 \\
\hline Emergency LSCS & 23 & 46 \\
\hline Vaginal delivery & 5 & 10 \\
\hline Laparotomy & 7 & 14 \\
\hline $\begin{array}{l}\text { Instrumental evacuation } \\
\text { or curettage }\end{array}$ & 5 & 10 \\
\hline Peripartum hysterectomy & 2 & 4 \\
\hline Hysterotomy & 1 & 2 \\
\hline Total & 50 & 100 \\
\hline
\end{tabular}

Here, (Table 7) and (Figure 3) shows that our hospital is a tertiary care center. Patients who require core obstetric

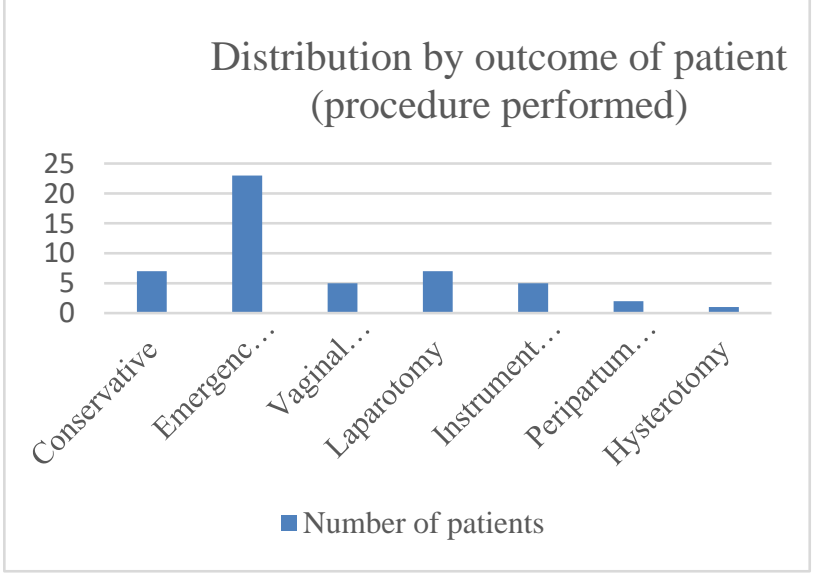

Figure 2: Distribution by the outcome of the patient (procedure performed). care without the need for any ionotropic, ventilatory support, multi-disciplinary involvement are shifted to the labor room, while more severe cases are shifted to the intensive care units namely the critical care unit. During this lockdown, patients with symptoms of COVID-19 infection or patients comes a containment area was shifted to the isolation ward after they were stabilized using necessary precautions. 18 patients were shifted to the labor room, while 21 were shifted to the isolation ward. 11 patients needed intensive care and were shifted to the CCU.

Table 7: Distribution by the level of care.

\begin{tabular}{|lll|}
\hline Shifted to & Number of patients & Percentage \\
\hline Labour room & 18 & 36 \\
\hline Isolation ward & 21 & 42 \\
\hline COVID ICU & 1 & 2 \\
\hline CCU & 10 & 20 \\
\hline Total & 50 & 100 \\
\hline
\end{tabular}

Here, (Table 8) shows Some of the unusual cases we encountered during the lockdown period were, a cervical tear in a case of PPH, ruptured tubal ectopic pregnancy, concealed abruption with IUD, unexplained thrombocytopenia, convulsions in the puerperal period, and a severely ill COVID 19 positive patient.

\section{Distribution of level of care}

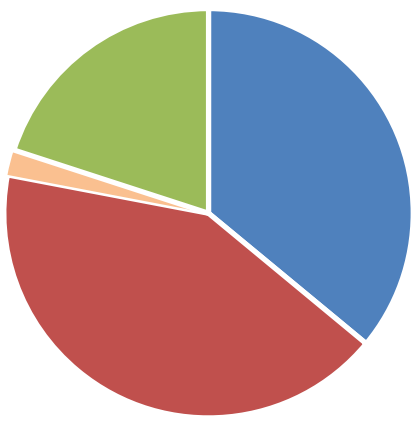

- Labour room

- Isolation

ward

COVID

ICU

Figure 3: Distribution of the level of care.

Table 8: Some unusual cases encountered during the lockdown.

\begin{tabular}{|c|c|c|c|c|}
\hline S. no. & Cases & $\begin{array}{l}\text { Term/Preterm/ } \\
\text { Post-abortal/Postdelivery }\end{array}$ & Mode of intervention & Outcome \\
\hline 1. & Cervical tear, atonic PPH, shock & Post delivery & $\begin{array}{l}\text { Laparotomy, cervical } \\
\text { reconstruction, internal } \\
\text { iliac ligation }\end{array}$ & Recovered \\
\hline 2. & $\begin{array}{l}\text { Ruptured tubal ectopic on } \\
\text { inotropes support }\end{array}$ & Early pregnancy & $\begin{array}{l}\text { Laparotomy, } \\
\text { salpingectomy }\end{array}$ & Recovered \\
\hline 3. & $\begin{array}{l}\text { Primi, term, concealed abruption, } \\
\text { IUD, no other risk factors }\end{array}$ & term & Vaginal delivery & Recovered \\
\hline 4. & Preterm, severely ill COVID & preterm & Emergency LSCS & Recovered \\
\hline
\end{tabular}




\begin{tabular}{|c|c|c|c|c|}
\hline S. no. & Cases & $\begin{array}{l}\text { Term/Preterm/ } \\
\text { Post-abortal/Postdelivery }\end{array}$ & Mode of intervention & Outcome \\
\hline & \multicolumn{4}{|l|}{ positive patient, prev 2 LSCS } \\
\hline 5. & $\begin{array}{l}\text { Central placenta previa, } 25 \text { weeks, } \\
\text { prev LSCS, anencephaly with } \\
\text { antepartum bleed. }\end{array}$ & Second trimester & $\begin{array}{l}\text { Laparotomy, } \\
\text { hysterotomy, internal iliac } \\
\text { ligation }\end{array}$ & Recovered \\
\hline 6. & Convulsions in puerperal period & Postnatal day 7 & $\begin{array}{l}\text { Conservative } \\
\text { management of } \\
\text { subarachnoid hemorrhage }\end{array}$ & Recovered \\
\hline 7. & $\begin{array}{l}\text { Primi,36 weeks with unexplained } \\
\text { thrombocytopenia }\end{array}$ & term & $\begin{array}{l}\text { Emergency LSCS for } \\
\text { meconium-stained liquor }\end{array}$ & Recovered \\
\hline
\end{tabular}

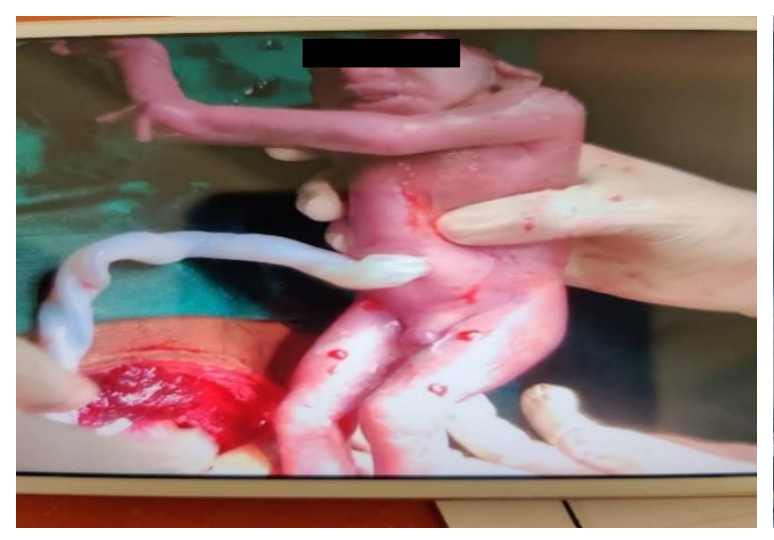

Figure 4: Anencephaly fetus- Mother had missed the NT scan due to pandemic, which led to delayed identification at 20 weeks

\section{DISCUSSION}

Fifty Obstetric emergency cases were analyzed to study the demographics, clinical characteristics, and outcomes of these patients and adopt management protocols in the management of a suspected COVID-19 obstetric emergency case. On analysis, the mean age of the patients studied was found to be 25.6 years. The mean gestational age of the preterm patients was around 35 weeks.

Most of them were preterm pregnancies $16(32 \%)$ and 14 $(28 \%)$ of them were term pregnancies. Twelve postnatal pregnancies presented, on various days of their postnatal period while 3 patients were of the postabortal state. The majority of the patients were primigravida, 17(34\%) in number. Twelve patients presented in the puerperal period.

The maximum number of emergencies was pregnancyinduced hypertension and its associated complications $(32 \%)$ which include imminent eclampsia, antepartum eclampsia, post-partum eclampsia, placental abruption. Post-partum hemorrhage including atonic and traumatic contributed to an emergency in 9 cases. Most of the studies done in this regard show labor and its complications as a primary cause of the emergency, obstetric hemorrhage was the second most common cause of obstetric emergencies.
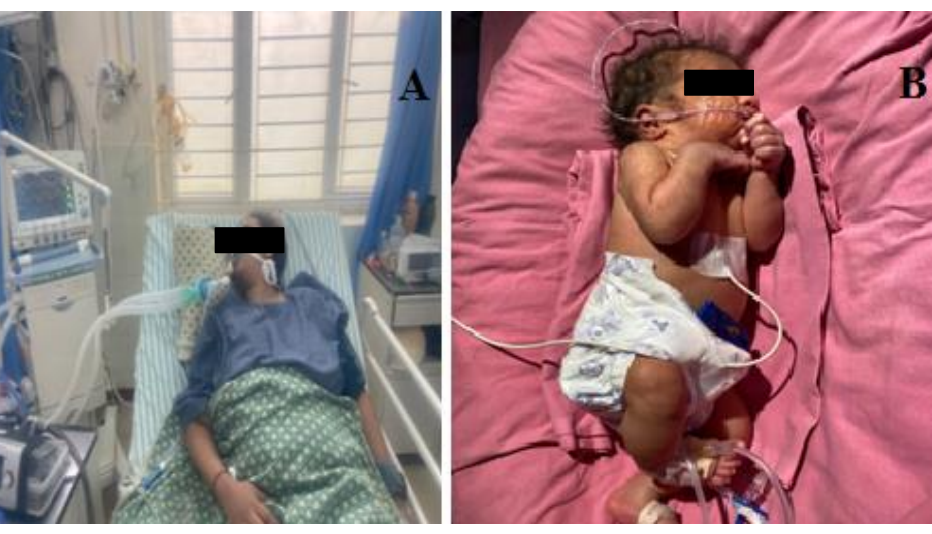

Figure 5: (A) COVID-19 positive mother (B) Her baby on post-op day 4

A total 23 individuals underwent emergency lower segment cesarean section while 5 of them had vaginal deliveries. 7 individuals were given medical line of management, in one case emergency hysterotomy was done. This finding is not similar to the other studies by the percentage of individuals who underwent vaginal deliveries were more compared to LSCS. Peripartum hysterectomy was done in two of the patients. Instrumental evacuation /curettage was done in $10 \%$ of the cases.14\% of the individuals were provided with conservative management, this involved blood transfusion, antibiotic therapy, intravenous fluidsmedically managed PPH, mgso4 therapy. This shows the importance of multidisciplinary involvement in obstetric emergencies. Among the study group $36 \%$ of the individual were shifted to the labor room from the emergency department while $42 \%$ of them were shifted to the isolation ward for observation. $6 \%$ of the patients were shifted to the COVID ICU and $22 \%$ the CCU out of a total of $28 \%$ required intensive care.

One severely ill COVID 19 positive preterm pregnant patient was managed at our department. She needed ICU care for ventilatory support. ${ }^{12}$ Four days later, she needed an emergency cesarean section for deteriorating medical condition. ${ }^{13}$ No intraoperative or postoperative complications were encountered. Mother and baby were discharged 14 days later. 
We experienced some unanticipated events during this lockdown, even in patients without any risk factors. They were PPH following vaginal delivery, birth asphyxia, sudden IUD, meconium staining, fetal distress, molar pregnancy, oligohydramnios, and IUGR post-partum eclampsia. This can be attributed to the fact that regular ANCs were not done during this lockdown due to various reasons like travel restrictions, reduced hospital staff, and the possibility of contracting the virus during hospital visits in COVID 19 times. Further, iron and calcium supplements were not taken properly leading to more cases of anemia and PIH. To add to this, anomaly scans were not done $\&$ even if they were done there was a delay in detecting anomalies. As a result, we had one case wherein anencephaly was detected at 24 weeks which otherwise could have been detected at 11 weeks of gestation.

Alertness and awareness among treating doctors may accelerate early referral and reduction in morbidity and mortality rates. ${ }^{14}$ The results of our study could help in creating appropriate management protocols in managing emergencies. However, pitfalls do exist in our system where transport, technical difficulties, availability of operative, and blood facilities create impossibilities at the final hour.

\section{CONCLUSION}

Pregnancy - the journey from conception till delivery is one with several hurdles, and each hurdle can be crossed depending on the patient's physiological condition, coexistent morbidities, and conditions unique to pregnancy. At the emergency department, a quick stabilization using necessary precautions like N95 respirators and gloves in all cases and PPE in suspected cases and an immediate call to the obstetrician is of utmost importance. This study will guide us to revise our existing emergency management protocols along with the new COVID guidelines and to develop strategies for training the primary healthcare doctors regarding early referral of emergency obstetric cases.

Funding: No funding sources

Conflict of interest: None declared

Ethical approval: Not required

\section{REFERENCES}

1. Campbell S, Lee C. Obstetric emergencies. In Obstetrics by Ten Teachers, S. Campbell and C. Lee, Eds. Arnold Publishers, 17th edition. 2000:303-17.

2. Avery M. Obstetric emergencies. Americ J Chine Medic. 2009;6(2): 42-6
3. Hospital-based triage of obstetric patients. Committee Opinion no. 667. American College of Obstetrics and Gynaecologists, Obstet Gynecol 2016;128:e16-9.

4. Siwatch S, Segal E, Goyal L. Hysterectomy- Indications and Associated Complications: An Indian Teaching Hospital Experience. Nepal J Obstet Gynaecol. 2014;7(2):17-20.

5. WHO, UNICEF, UNFPA, World Bank (2012) Trends in maternal mortality: 1990 to 2010. Available at: https://www.who.int/reproductivehealth

/publications/monitoring/9789241503631/en/. Accessed on 20 May 2020.

6. The Royal College of Midwives, Royal College of Obstetrics and Gynaecology, Royal College of Paediatrics and Child Health, Royal College of Anaesthetists. Coronavirus COVID-19 Infection in Pregnancy; 2020;5.

7. Favre G, Pomar L, Qi X, Nielsen-Saines K, Musso D, Baud D. Guidelines for pregnant women with suspected SARS-CoV-2 infection. Lanc Infect Disea. 2020;20(6):652-3.

8. American College of Obstetricians and Gynaecologists. Novel Coronavirus 2019 (COVID-19) Practice Advisory. Available at: https://www .acog.org/clinical/clinical-guidance/practiceadvisory/articles/2020/03/novel-coronavirus-2019. Accessed on 05 April 2020.

9. Government of India, Ministry of Health \& Family Welfare, Directorate General of Health Services (EMR Division). Revised Guidelines on Clinical Management of COVID-19. Available at: https://www.mohfw.gov.in/pdf/RevisedNationalClinical ManagementGuidelineforCOVID1931032020.pdfAcces sed on 05 April 2020.

10. Centers for Disease Control and Prevention. Interim Considerations for Infection Prevention and Control of Coronavirus Disease 2019 (COVID-19) in Inpatient Obstetric Healthcare Settings. Available at: https://www.cdc.gov/coronavirus/2019-ncov/hcp/ inpatient-obstetric-healthcare-guidance.html. Accessed on 05 April 2020.

11. Zhao X, Jiang Y, Zhao Y, Xi H, Liu C, Qu F, et al. Analysis of the susceptibility to COVID-19 in pregnancy and recommendations on potential drug screening. Europ J Clinic Microbiol Infecti Diseas. 2020;23:1

12. Chawla S, Nakra M, Mohan S, Nambiar BC, Agarwal R, Marwaha A. Why do obstetric patients go to the ICU? A 3-year-study. Medic J Armed Forc Ind. 2013;69(2):134-7.

13. Guidance of management of pregnant women in COVID 19 Pandemic; Indian Council for Medical Research and National Institute for Research in Reproductive Health, Mumbai April 2020.

14. Abha S, Lily N, Obstetric emergencies: Role of Obstetric Drill for a better Maternal Outcome J Obstet Gynaecol India.2012;62(3):291-6.

Cite this article as: Vasudhar A, Anita S, Patil GL, Shridevi AS, Pujar TV, Renuka. Obstetric emergen cies during the COVID 19 lockdown period: a case series. Int J Reprod Contracept Obstet Gynecol 2020;9:4682-7. 